\title{
Language Attrition Theory on English Language Teaching
}

\author{
Rui LIU ${ }^{1,2}$ \\ ${ }^{1}$ Grade 2013 in College of Foreign Languages, Gannan Normal University \\ ${ }^{2}$ English Department, Ganzhou Teachers' College, Ganzhou 341000, China
}

\begin{abstract}
Language attrition is a reverse process of language learning. Language attrition is caused by many factors and the available information, including the summary of the level before abrasion, erosion of time, the target language exposure, age, foreign language learning, emotional factors and literacy (NI Chuanbin, 2006). Language attrition and language acquisition are the two processes of learning language and both mutually demise, and some scholars have drawn a conclusion that language acquisition and language attrition have a significant negative correlation mutually. The traditional theory of language acquisition, based on the linear theory, explains that language learning is a chronological order from easy to difficult, and gradually improved. Researchers who focus language attrition have proposed the theory of dynamic systems, emphasizing the language system interaction with the environment and continuing to carry out their own adjustments and changes, and also more emphasis has been evolving constitute language system.
\end{abstract}

Keywords: Language Dynamic System; Younger Age; the Process of Evaluation

\section{Introduction}

China's foreign language education was generally originated in the late Qing dynasty, and had undergone unending changes from the westernized Chinese style in the late Qing dynasty to the humanities education during the period of the republic of China, and the model of "emphasize science and neglect liberal arts" during the establishment period of the People's republic of China. However, all changes did not deviate from the same essences, namely, the cultivation of four fundamental English abilities (listening, speaking, reading and writing) and the study of profound learning.

The history of China's foreign language education has a long history and still develops constantly. Today, people have to admit that the current foreign language education has deviated from the original essences while seriously, objectively thinking about the current learning situation of foreign language students. The learning situation of English learners is not optimistic.

Seen from the viewpoint of life-span psychological linguistics, language acquisition includes not only acquisition, but also attrition and consumption; not only improvement and progress, but also hysteresis and degradation. Attrition, consumption, hysteresis, and degradation are important parts of the whole language development (CAI Hansong, 2001). Therefore, language acquisition and language attrition can be called as "twin brothers". China's foreign language education only pays attention to language acquisition and the improvement of language ability, but ignores language attrition, degradation, and loss. A very important reason why China's English education is less than satisfactory is that the existence of language 
attrition is overlooked. From the perspective of language attrition, the current reform of the fundamental English education is re-examined, so as to make overall plans and take all factors into consideration and also deepen the overall knowledge and comprehensive understanding of the problems.

\section{The correlation theory of language attrition}

Language attrition means that the ability of bilingual or multilingual users to apply the languages will gradually decline with the passage of time because language application is less or stopped (NI Chuanbbin, YAN Junrong, 2006: 50). It is a mental phenomenon in the process of language acquisition, but also an inevitable natural phenomenon of learners in the process of adapting to the external environment.

The study of foreign language attrition was started in the 1980s, and now has become a new field of language acquisition research. As an inverse process of language acquisition, language attrition puts forward the theory of dynamic system, the theory of language interference, and the theory of retaining paradigm, regression assumption, and key threshold hypothesis by summing up the attrition characteristics and loss phenomena of all mother tongues and foreign languages. In addition, some scholars, such as NI Chuanbin and YAN Junrong, discuss the factors affecting language attrition. The related theories involved in this paper are as follows:

\subsection{The theory of dynamic system}

The theory of dynamic system thinks that language is a dynamic, chaos, and complex system, and language development is a dynamic, adaptive, and unpredictable process. Language change is restricted by the initial conditions, reflected by the equilibrium or non-equilibrium state of introduction and decided by the internal and external resources of cognition and society, so that a nonlinear variation and a growing relevance are demonstrated. The competition and interaction between innumerable individual systems result in a self-organizing system, but also build the overall language communication paradigm.

\subsection{The theory of retaining paradigm}

The theory of retaining paradigm, originated from cognitive psychology, is a new development of language acquisition about memorizing and forgetting strategy. It thinks that the knowledge learners learned previously had been forgotten after a period of time, but the language knowledge stored in the brain of them will not disappear. However, the acquisition of the old knowledge may sleep because of a long time, but can be re-memorized and taken once it is triggered by the external mechanism.

\section{Rethinking English teaching from the perspective of language attrition}

A questionnaire survey, made by the author about the English learners' interest in English learning, showed that $63 \%$ of the students thought their goals to learn English were unclear and they felt confused. A questionnaire survey, made by NI Chuanbin, showed that all the students thought learning English was a waste of time and energy, and most of them said there was not any relationship between their future work after graduation and their proficiency in English. Many other investigations showed that English teaching in China seemed to have walked into a dead end. Based on the related theories of language attrition, the following several problems can be concluded.

\subsection{The absence of emotion and the low interest of students in learning}

Social emotional factors mainly focus on the learners' attitude and motivation. According to the study of NI Chuanbin and YAN Junrong, the direct effect of emotional factors on the degree of language attrition was 0 , and the indirect and overall effect was -0.02 . The result proves that emotional factors play an extremely tiny negative 
indirect effect on the degree of language attrition, but a positively direct effect $(0.21)$ and a negatively indirect effect on foreign language exposure; the overall effect strength was 0.34 . These indicate that emotional factors mainly have a direct effect on foreign language exposure. There is no exception to the conclusion of Gardner based on structural equation model. That is, positive emotional factors can significantly increase foreign language exposure to subjects.

\subsection{Younger-age trend and inefficiency in English learning}

Age is an important factor affecting language attrition. Hansen (1980) found that there were differences between children and adults in foreign language attrition. She used to study two preschool children deeply in the United States. The two children stayed in India with their parents for three times and had learned North India-Urdu language. Every time in India, the local children thought the two could speak the local language almost like them. By contrast, the mothers of the two children were far worse.

Concerning about the role of children's age in language attrition, Cohen, Hansen, Hansen-Strain, Kaufman and Yukawa had done a study and drawn up a similar conclusion: the younger is much faster than the older in language attrition. The survey of Olshtain found that the attrition of the children in 5 7 years old was much faster than that in 8 14 years old, and also $8 \sim 9$ years old is a key period for the foreign language attrition of children.

Reviewing China's English education, teachers in many places are very anxious to spoil students by excessive enthusiasm, making Younger-age trend more and more significant in English learning. Too early language input can increase the children's study burden and discourage children's confidence and interest in learning, so that they feel averse and disgusted mentally when they enter into the formal English learning. This goes against the systematic English education. From the perspective of the benefit of investment, Younger-age trendy English learning increases the education investment, prolongs the learning period, and invisibly reduces the learning efficiency. Ultimately, the mental anxiety of students is caused and language attrition is further accelerated.

\subsection{Rigid teaching model and the passive knowledge receiving of students}

In terms of teaching contents, the resistance of different language skills to attrition is not the same. Barrick's study (1984) showed that accepting skills (listening and reading) were more resistant than output skills (speaking and writing) to attrition. In terms of teaching methods, Hansen (1999) thought that the language ability learned by ostensive teaching method is more resistant than that by direct teaching method to attrition.

Re-examining the current English teaching, the idea of exam-oriented education is still very common. Under the guidance of all sorts of entrance exams, educational objective is intensively utilitarian, and teachers have to accelerate the process of teaching in order to complete the teaching task under the condition of limited class hours and they mostly apply the "cramming" teaching method. Finally, the students cultivated in English education should be proficient in exam-taking skills, but poor in language application ability. This is a widespread phenomenon among English learners in China.

\section{Seeking the ways of solving the problems in English teaching from the perspective of language attrition}

The above problems in China's English education, especially in fundamental English teaching, can be solved using the following several ways. 


\subsection{Rising English teaching to the height of cultural teaching and arousing the learning motivation of students}

Learning English, mainly focusing on the big background of global economic integration, aims at training the inter-disciplinary talents who possess a solid basic foundation of English, strong language skills, and a good command of national cultural exchanges. Language education not only values the English knowledge acquisition by students, but also cultivates the comprehensive language ability of students in listening, speaking, reading, writing, and translation, so that the transition from exam-oriented education to quality-oriented education is accomplished. In the general education level, the guidance in moral quality and mental quality must be provided for students, and also "promoting the development of mind" and "improving the comprehensive cultural literacy" must be implemented, so as to help students achieve an all-round development in social emotion, learning strategies and cultural awareness. Therefore, English teaching is language teaching, cultural teaching, but also quality-oriented education to cultivate humanistic spirit and international consciousness, and one of its aims is to let students master English and carry out cross-cultural communication using the language.

\subsection{Respecting individual differences and taking a diversified teaching strategy according to the resistance of different language skills to attrition}

According to the theory of dynamic system, language learning needs the coordinated development of the internal and external resources of learners. In internal resources, learning attitude and motivation are the main influencing factors, which play a very important role in the improvement of learning efficiency and the cultivation of autonomous learning ability. Teaching form must be converted from explanation-based teaching to communicative teaching in which students are the main subjects and guided by teachers; teaching contents must be changed from language knowledge to language application ability and from exam-center to quality-center; teaching activities are diversified to really stimulate students' real innate desire to learn.

\subsection{Changing the evaluation way and reducing the attrition effect}

The single receptive skills test is converted to multiple forms of test. For example, a combination of written exam with oral exam and a combination of classroom activities with extracurricular activities can promote the students with different learning styles, different levels and different characteristics to show them and experience success, so as to maintain the interest and motivation in learning English. Education evaluation way is converted from a blindly summative evaluation model to the combination of process evaluation with summative evaluation and must pay more attention to the learning state of the students at ordinary times. The learning effect can be only ensured by a good process evaluation.

\section{Conclusions}

Language attrition is a natural phenomenon in the process of language acquisition and provides a new perspective for English teaching. It is also blank in the traditional English teaching. Throughout these years of English teaching in China, many parents and training institutions don't respect the law of language teaching and often blindly infuse learning tasks in recent years, making the language learning period prolonged just because of their great ambitions for the child.

\section{References}

[1] Yunxuan KUANG. Enlightenments from Language Attrition to College English Teaching in China [J]. Journal of Exam, 2012, 41: 81-83. 
[2] Jingyao LI. Study on the Relearning Hypothesis of Middle School English Vocabulary Attrition [D]. Shandong Normal University, 2013.

[3] Jingshu LI. Enlightenments from the Study of Language Attrition to the Reform of College English Teaching [J]. Journal of Shenyang Normal University (Social Science Edition), 2011 03:142-144.

[4] Baohong LI, Wei HONG. Enlightenments from the Study of Language Attrition to
English Teaching and Acquisition [J]. DAJIA, 2011, 20: 148-149.

[5] Yanyang LI. Enlightenments from the Study of Language Attrition to Specialized English Teaching [J]. Journal of Yangtze University (Social Science Edition), 2014, 07: 126-128+132.

[6] Aihua CHEN. Enlightenments from Language Attrition to English Teaching in China $[\mathrm{J}]$. Journal of Chifeng Institute (Natural Science Edition), 2011, 06: 264-266. 